\title{
Peri-Umbilical Lymphangioma
} Circumscriptum Associated with IntraAbdominal Lymphatic Malformations

\author{
Bhavna Singh Koraisha Hoosen \\ Department of Dermatology, Nelson R. Mandela School of Medicine, University of \\ KwaZulu-Natal, Durban, South Africa
}

\section{Keywords}

Lymphatic malformations · Lymphangioma circumscriptum

\begin{abstract}
A 12-year-old African female presented with a 6-year history of relatively asymptomatic umbilical lesions. On clinical examination, the lesions were papillomatous, violaceous nodules and translucent papules with a serosanguineous discharge. The lesions emanated from the umbilicus and extended peri-umbilically. Histopathology confirmed a lymphangioma and MRI and $\mathrm{CT}$ imaging revealed multiple intra-abdominal lymphatic malformations. The patient was referred to plastic surgery for further management. Due to the extent of involvement, surgical resection was an option but currently the therapeutic approach is sclerotherapy with bleomycin.

\section{Introduction}

Lymphatic malformations (LM) include a spectrum of disorders (Table 1) [1]. Lymphangiomas are congenital, benign hamartomatous malformations of the lymphatic system. Lymphangioma circumscriptum (LC), a microcystic LM, often favours the proximal limbs, chest, and oral mucosa. We describe the case of a young, African female who presented with a peri-umbilical LC arising in association with underlying intra-abdominal LMs. 

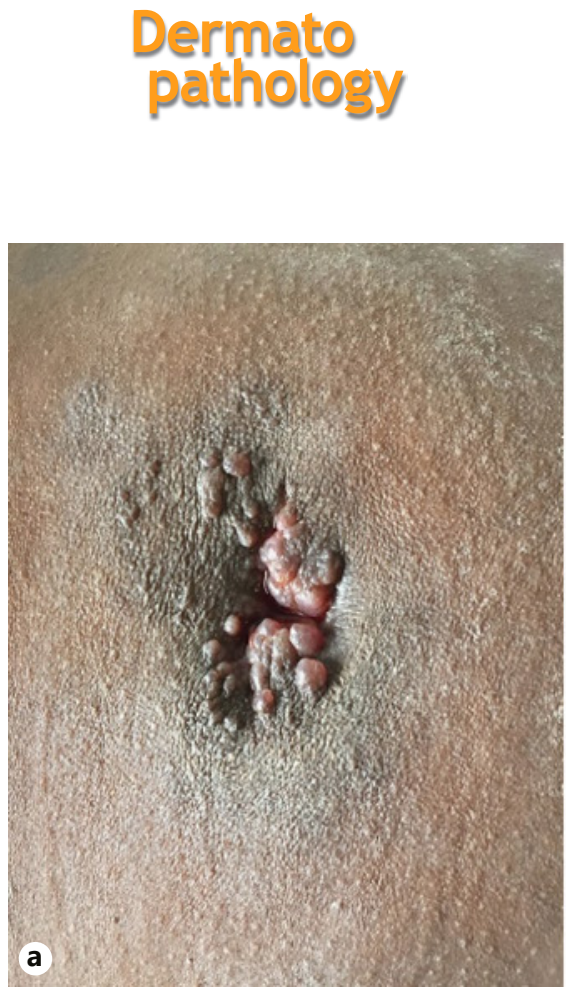
www.karger.com/dpa

Singh and Hoosen: Peri-Umbilical LC Associated with Intra-Abdominal Lymphatic Malformations
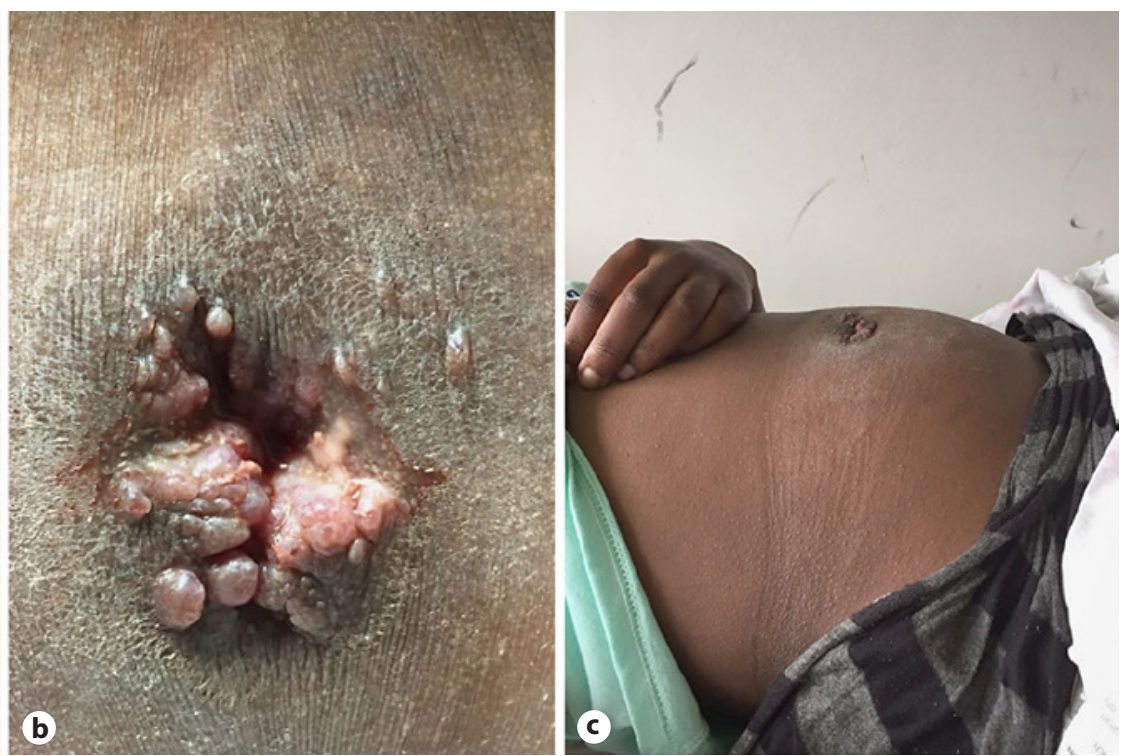

Fig. 1. a-c Clinical presentation.

Table 1. Classification of lymphatic malformations

\author{
Common (cystic) LMs \\ Macrocystic \\ Microcystic \\ Combined \\ Generalised lymphatic anomaly \\ LM in Gorham-Stout disease \\ Channel-type LMs \\ Primary lymphoedema \\ Others
}

Adapted from Wassef et al. [1]. LM, lymphatic malformation.

\section{Case Report}

A 12-year-old African female presented with a 6-year history of relatively asymptomatic umbilical lesions. On clinical examination, the lesions were papillomatous, violaceous nodules and translucent papules with a serosanguineous discharge. The lesions emanated from the umbilicus and extended peri-umbilically. There was associated mild abdominal distension with minimal abdominal tenderness (Fig. 1a-c). There was no hepatosplenomegaly and there were no other significant clinical findings.

LC was considered as a primary diagnosis and a skin biopsy was performed to exclude extra-uterine endometriosis and Sister Mary Joseph nodule. Magnetic resonance imaging (MRI) and contrast tomography (CT) imaging revealed multiple intra-abdominal LM (Fig. 2, 3). LC was confirmed on histology (Fig. 4). Immunohistochemistry demonstrated D2-40 and CD31 positivity (Fig. 5). The findings of investigations are summarised in Table 2.

The patient was referred to plastic surgery for further management. Due to the extent of involvement, surgical resection was an option but currently the therapeutic approach is sclerotherapy with bleomycin. 


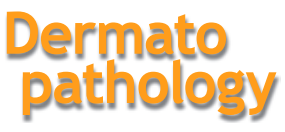

\begin{tabular}{l|l}
\hline Dermatopathology 2019;6:105-110 \\
\hline DOI: 10.1159/000496387 & $\begin{array}{l}\text { ○ 2019 The Author(s). Published by S. Karger AG, Basel } \\
\text { www.karger.com/dpa }\end{array}$ \\
\hline
\end{tabular}

Singh and Hoosen: Peri-Umbilical LC Associated with Intra-Abdominal Lymphatic Malformations
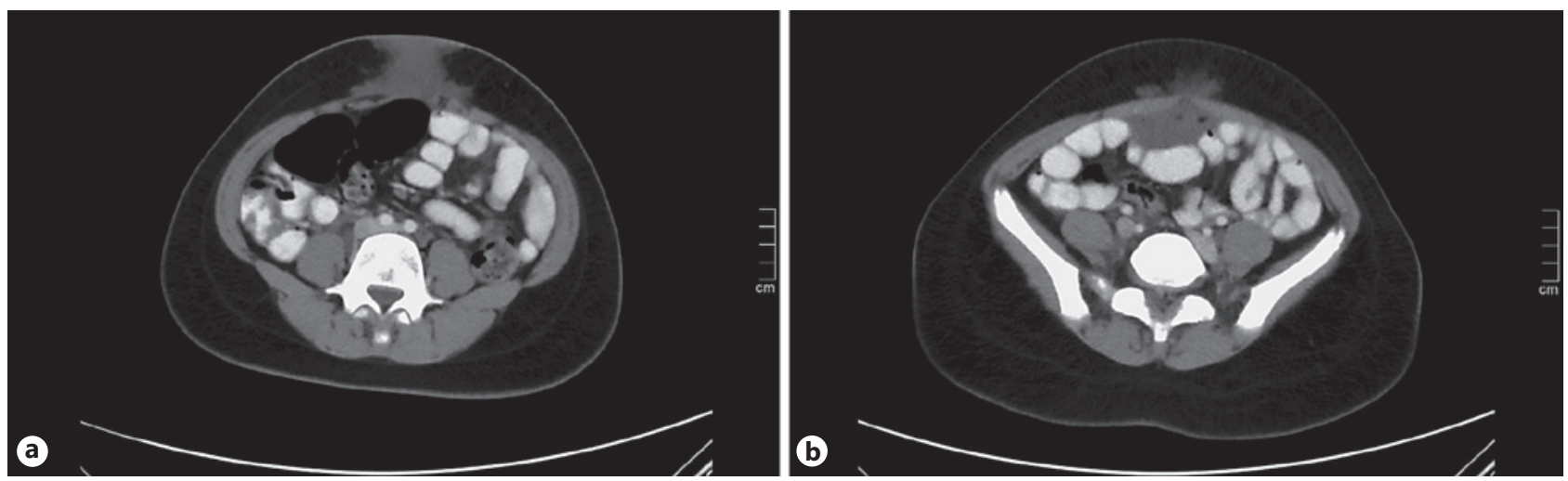

Fig. 2. a, b Post-contrast CT images demonstrating a hypodense lesion extending from the anterior abdominal wall to the mesentery.
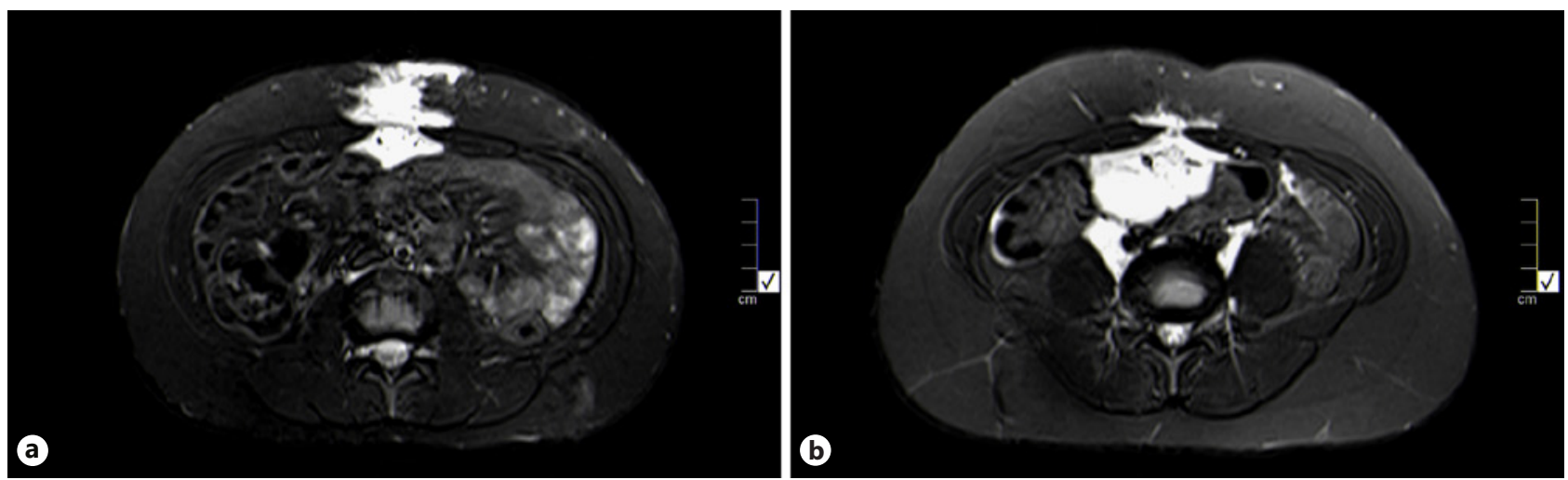

Fig. 3. a, b MRI demonstrating hyperintense fluid-filled lesions extending into the peritoneum.
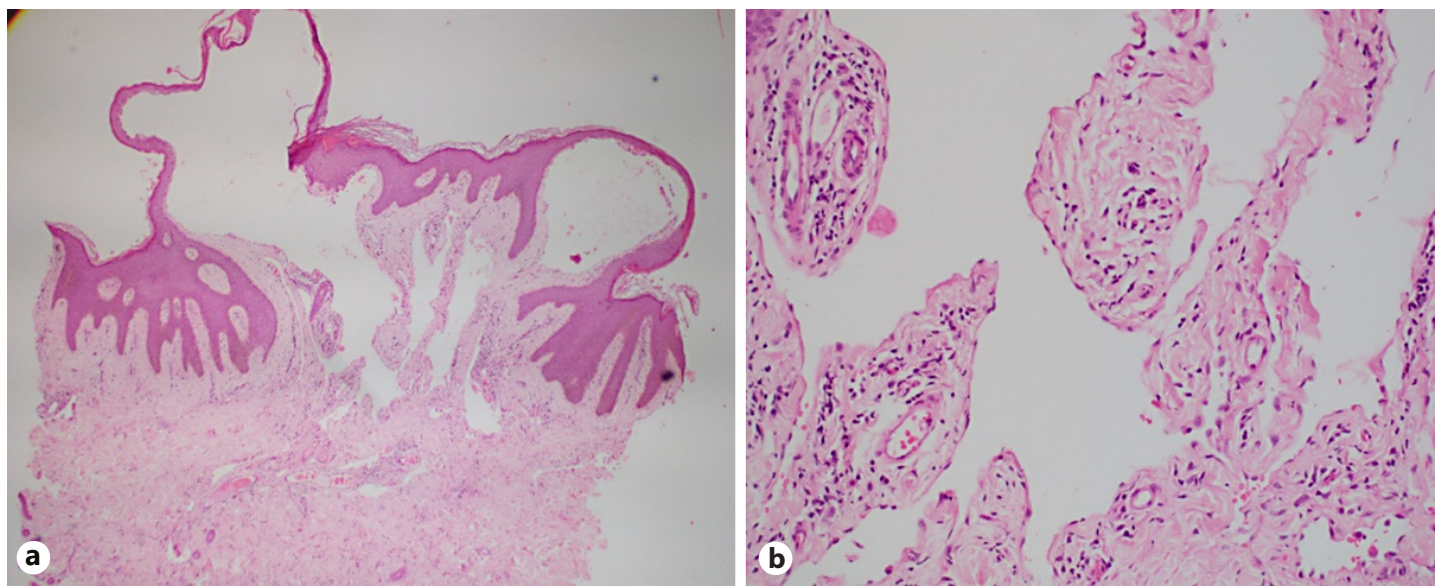

Fig. 4. Histology demonstrating dilated lymphatic channels on (a) low power and (b) high power. 

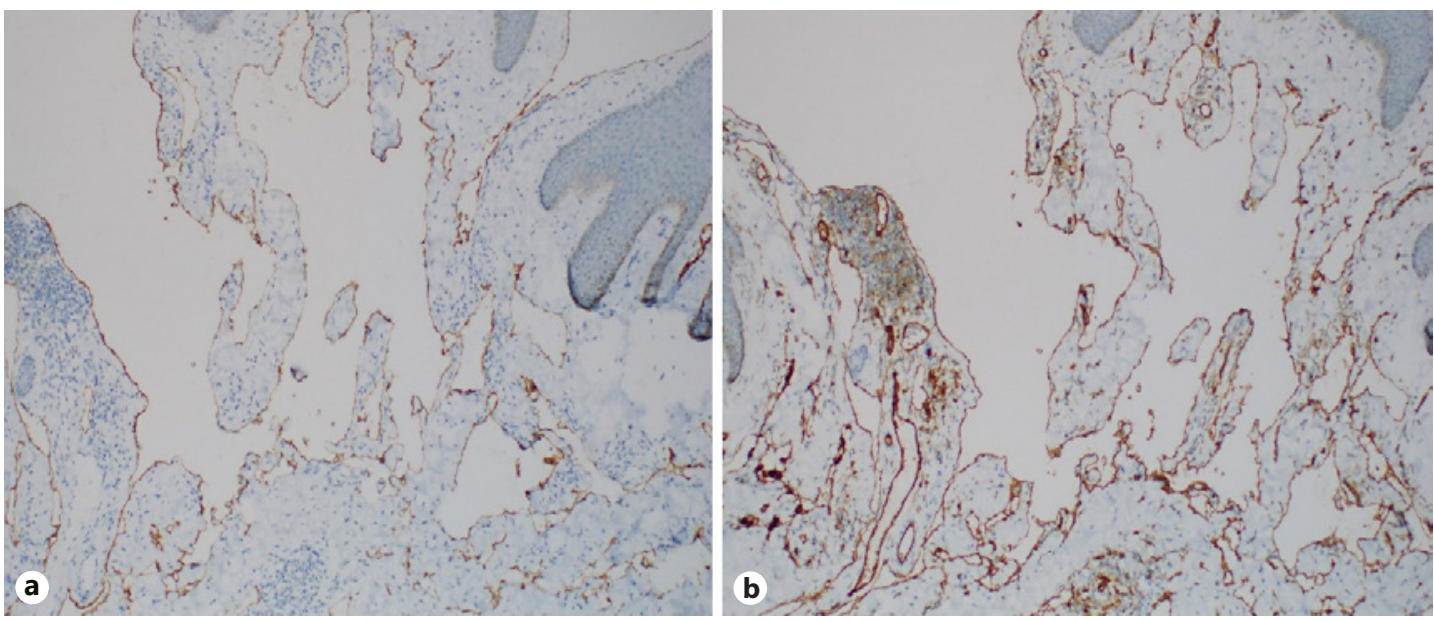

Fig. 5. Immunohistochemistry demonstrating (a) D2-40 positivity and (b) CD31 positivity.

Table 2. Summary of investigations and results

\begin{tabular}{|c|c|c|}
\hline Imaging & Blood investigations & Histopathology \\
\hline X-rays (abdomen and chest): normal & $\begin{array}{l}\text { FBC/Diff/U\&E/LFT/ESR: } \\
\text { normal }\end{array}$ & $\begin{array}{l}\text { H\&E: polypoid vascular lesion } \\
\text { composed of thin walled, ectatic } \\
\text { lymphatic channels lined by } \\
\text { flattened endothelial cells (Fig. 4) }\end{array}$ \\
\hline Ultrasound (abdomen and pelvis): normal & HIV Elisa: negative & $\begin{array}{l}\text { Immunohistochemistry: positive } \\
\text { D2-40 (Fig. 5a) and CD31 (Fig. 5b) }\end{array}$ \\
\hline $\begin{array}{l}\text { CT (abdomen): multiple hypodense lesions } \\
\text { suggestive of lymphangiomas (Fig. 2) }\end{array}$ & Hepatitis screen: negative & \\
\hline $\begin{array}{l}\text { MRI (abdomen): intra-abdominal extension } \\
\text { of lesion; no invasion of organs or other } \\
\text { systems (Fig. 3) }\end{array}$ & & \\
\hline
\end{tabular}

\section{Discussion}

LC is a microcystic LM consisting of ill-defined aggregates of relatively small, abnormal lymphatic channels and is the most common type of LM. Lesions present as crops of thinwalled vesicles mimicking "frog spawn." Additional clinical findings are intermittent swelling, haemorrhage, and leakage of clear fluid from superficial vesicles [2].

The classic variety of LC is seen at or soon after birth, is often larger than $1 \mathrm{~cm}^{2}$ and commonly presents over the proximal limbs. The localised form can be seen at any age and is smaller than $1 \mathrm{~cm}^{2}$. LC can occur as a congenital or acquired form secondary to chronic obstruction of lymphatics that can manifest at any age [3].

Sites favoured include the proximal limbs and chest, though it can occur in any cutaneous site or in the mouth, including the tongue, buccal mucosa, lips, and oral floor. Vulvar LC has also been reported as a rare presentation $[4,5]$.

There have, however, been no reported cases of LC occurring peri-umbilically. A periumbilical dermatosis may be significant in heralding certain intra-abdominal diseases including neoplasia [6]. Other reported conditions sharing a similar clinical presentation and 
anatomical location to our case include benign lymphangiomatous papules of the skin due to obstructed lymphatic flow caused by an ovarian fibroma [6], multilocular mesothelial proliferation (MMP) of the umbilicus [7], and adenomatoid tumour of the umbilicus [8]. MMP, also known as multicystic peritoneal mesothelioma, may mimic a macrocystic LM intra-abdominally [9].

Histologically, LC lesions display enlarged, distorted, irregular lymphatic channels with varying numbers of smooth muscle cells in their walls and a very thin endothelium [2]. Endothelial cells are immunohistochemically positive for endothelial markers D2-40 and lymphatic vessel endothelial receptor 1 . D2-40, a monoclonal antibody, was initially described as a selective marker of germ cells and lymphatic endothelium but is also found to be a useful marker of cells of a mesothelial phenotype [10]. This rationalises MMP, for example, as a differential diagnosis for a cystic lesion. Besides histopathological findings and other immunohistochemical markers such as cytokeratin 5/6, the use of electron microscopy in identifying ultrastructural findings and cell type may be useful in differentiating such cases [9].

Imaging modalities of choice for LC include ultrasonography, MRI and CT. MRI is indicated to assess the extent of lymphangioma and its relation to neighbouring organs. CT is helpful to delineate angiomatous components.

Surgery is the treatment of choice for LC though recurrences are common [4]. Other techniques that are often used in combination include laser therapy (e.g., $\mathrm{CO}_{2}, \mathrm{Nd}: \mathrm{YAG}$ ), radiofrequency ablation, and cryoablation. Sclerotherapy using agents such as bleomycin, doxycycline, and ethanol is an alternative treatment option [3].

\section{Conclusion}

LC is an LM often presenting with localised crops of vesicles commonly over the proximal limbs, chest, and oral mucosa. We present a unique case of peri-umbilical lesions associated with intra-abdominal LMs.

\section{Acknowledgements}

The authors wish to thank the Department of Anatomical Pathology, National Health Laboratory Service, Inkosi Albert Luthuli Central Hospital for the histopathology images, and the Department of Radiology, Inkosi Albert Luthuli Central Hospital for radiographic images.

\section{Statement of Ethics \\ Consent was obtained for use of the subject's photographs.}

\section{Disclosure Statement}

The authors have no conflicts of interest to declare. No funding was received. 


\section{References}

1 Wassef M, Blei F, Adams D, Alomari A, Baselga E, Berenstein A, et al.; ISSVA Board and Scientific Committee. Vascular Anomalies Classification: Recommendations from the International Society for the Study of Vascular Anomalies. Pediatrics. 2015 Jul;136(1):e203-14.

2 Baselga E. Vascular malformations. In: Bolognia JL, Schaffer JV, Cerroni L, editors. Dermatology. 4th ed, revised. London: Elsevier; 2018. vol. 2; p. 1819-21.

3 Kudur MH, Hulmani M. Extensive and invasive lymphangioma circumscriptum in a young female: A rare case report and review of the literature. Indian Dermatol Online J. 2013 Jul;4(3):199-201.

4 Uçmak D, Aytekin S, Sula B, Akkurt ZM, Türkçü G, Ağaçayak E. Acquired vulvar lymphangioma circumscriptum. Case Rep Dermatol Med. 2013;2013:967890.

5 Akhavan S, Agah J, Nili F. Congenital lymphangioma circumscriptum of vulva presenting as multiple giant mass lesions: a case report and literature review. J Obstet Gynaecol Res. 2018 May;44(5):978-82.

6 Bodet D, Rodríguez-Cano L, Bartralot R, Mollet J, Medina A, Heras C, et al. Benign lymphangiomatous papules of the skin associated with ovarian fibroma. J Am Acad Dermatol. 2007 Feb;56(2 Suppl):S41-4.

7 Konstantinova AM, Michal M, Kacerovska D, Kazakov DV. Multilocular mesothelial proliferation involving the skin of the umbilicus. Am J Dermatopathol. 2013 Dec;35(8):856-8.

8 Adem C, Schneider M, Hoang C. Pathologic quiz case: an unusual umbilical mass. Arch Pathol Lab Med. 2003 Jul;127(7):e303-4.

9 Mennemeyer R, Smith M. Multicystic, peritoneal mesothelioma: a report with electron microscopy of a case mimicking intra-abdominal cystic hygroma (lymphangioma). Cancer. 1979 Aug;44(2):692-8.

10 Chu AY, Litzky LA, Pasha TL, Acs G, Zhang PJ. Utility of D2-40, a novel mesothelial marker, in the diagnosis of malignant mesothelioma. Mod Pathol. 2005 Jan;18(1):105-10. 